\title{
TSUNAMI RESONANCE IN THE PALMA DE MAJORCA BAY AND HARBOUR INDUCED BY THE 2003 BOUMERDES-ZEMMOURI ALGERIAN EARTHQUAKE (WESTERN MEDITERRANEAN)
}

\author{
J. Vela ${ }^{1}$, B. Pérez ${ }^{1}$, M. González ${ }^{2}$, L. Otero ${ }^{2}$, M. Olabarrieta ${ }^{2}$, M. Canals ${ }^{3}$ and J.L.Casamor ${ }^{3}$ \\ During the tsunami of May 2003 in the Balearic Islands, generated by the Algerian earthquake, most of the damage \\ and economic losses occurred inside the harbours, due to high frequency oscillations of relatively large amplitude, \\ combined effect of the tsunami and local resonances. It can be said in fact that this was the more important effect at \\ the islands, where no important inundations is known to have occurred outside the harbours, showing up that even \\ tsunamis with low amplitudes can cause serious damages due to resonance effects. Several tide gauges recorded the \\ seismic-generated tsunami, so comparison of simulations and observations became possible, and made this event a \\ very interesting case for modeling experiments. The main objectives of this work is to understand how was the energy \\ transformation of the tsunami from the source area to the Palma de Mallorca bay and harbour, and to verify if a \\ resonance phenomenon was induced in the harbour.
}

Keywords: tsunami; resonance; modeling; tide gage; comcot

\section{INTRODUCTION}

The 21rst of May 2003 a small tsunami (referred from here onwards as the 2003 Western Mediterranean tsunami) struck the Balearic Islands shores and coastal infrastructures after an earthquake offshore Algeria, known as the Boumerdès-Zemmouri earthquake. The earthquake occurred as a consequence of the subduction of the Eurasian plate under the African one. Initial estimates of the earthquake parameters indicate that it started at 18:44:30 UTC with the epicentre at $36.93 \mathrm{~N}, 3.58 \mathrm{E}$ and an initial magnitude of $\mathrm{Mw}=6.8$ according to the Harvard CMT solution.

Several generation mechanisms have been suggested for Boumerdès-Zemmouri earthquake, leading to different source parameters. Field studies by Meghraoui et al. (2004) and tele-seismic wave analysis studies by Yagi (2003), suggest that the magnitude of the earthquake likely was stronger than the initial estimate. Wang and Liu (2005), Alasset et al. (2006) and, more recently, Sahal et al. (2009) have performed numerical simulations of the event.

All tide gauges in the Western Mediterranean Basin recorded the resulting sea level oscillations, with the largest amplitudes being detected at Palma and Sant Antoni harbours, in the islands of Majorca and Ibiza, respectively. The first crest of the small tsunami reached Palma tide gauge 51' after the earthquake, at 19:35 UTC, with an initial amplitude of $\sim 20 \mathrm{~cm}$, which increased up to $55 \mathrm{~cm}$ about 110 ' later, thus yielding a total amplitude of $\sim 1.10 \mathrm{~m}$. The initial crest arrived at 19:45 at Sant Antoni 61' later, with up to $1.10 \mathrm{~m}$ of total amplitude. At the harbour of Ibiza city, the first arrival was at 19:34 UTC, i.e. one minute before Palma, with a total amplitude of $\sim 76 \mathrm{~cm}$ peaking also $\sim 110^{\prime}$ later. Sête, in southern France, detected the first arrival 126' later at 20:50 UTC, thought the amplitudes was very small as for the rest of tide gauges in the region located at Barcelona, Valencia, Alicante, Ajaccio, Toulon, Marseille, Livorno and other harbours. It is to be noted that the sampling frequency of the tide gauges ranged from 1' (e.g. Palma) to 2' (e.g. Sant Antoni and Sête) to even 5' (e.g. Ibiza), what could lead to an underestimation of the tsunami amplitude for the latter.

The damages generated by the 2003 Western Mediterranean tsunami in the Palma harbour concentrated in the northern basin where several pleasure and sailing boats sank between Sant Magí dock and the Royal Yatch Club (Fig. 1). The shallow water depth in this part of the harbour eased the sinking of the boats, as they were quickly moved up and down by the oscillations easily hitting the bottom and breaking. Also the seaside promenade in this part of the harbour was severely affected by the tsunami. A second highly impacted area was the "Espigón Consigna" (literally meaning the "leftluggage office breakwater"), in the commercial quays, where the tsunami waves took off an oil container and other objects (Fig. 1). Other harbours along the islands' shores reported significant

\footnotetext{
${ }^{1}$ Puertos del Estado. Avda. del Partenón, 10 - 28042 Madrid. Spain

2 Environmental Hydraulic Institute, IH Cantabria, Universidad de Cantabria, E.T.S.I. Caminos Canales y Puertos, Avd. los Castros S/N, 39005 Santander, Spain

${ }^{3}$ GRC Geociències Marines, Departament d'Estratigrafia, Paleontologia i Geociències Marines, Universitat de

Barcelona, Campus de Pedralbes, C/Martí i Franquès, s/n, 08020 Barcelona, Spain
} 

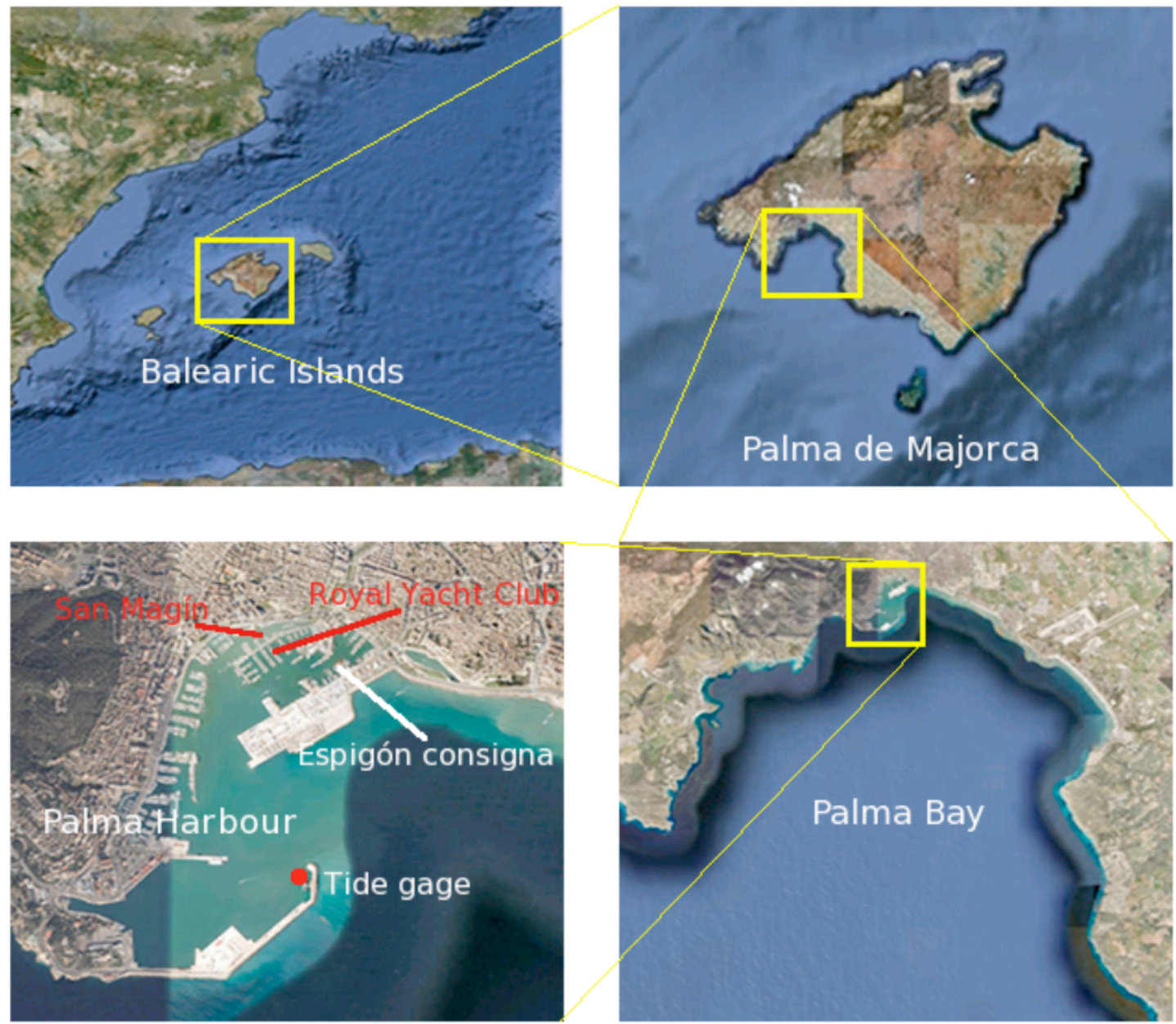

Fig 1. Area of study: bay and harbour of Palma. Bottom, left: map of Palma harbour in Palma bay, and the areas affected by the tsunami of May 2003. Several boats sank in San Magín dock.

material damage, especially Maó in Minorca Island where unfortunately no sea level records are available. Noticeably, no relevant flooding was reported off the harbours.

It is thought that the damages reported in the Palma harbour result from a resonance phenomenon with noticeable amplifications of wave heights in its northern basin, which a priori is the "most protected" part of the harbour. Resonance is a well-known problem inside harbours that occurs when the natural oscillation mode associated to a determined eigenperiod is similar to the forcing period. The natural periods of oscillation depend on the water depth and the geometry of the body of water, so that the study of resonance effects in the bay and harbour of Palma using numerical simulations requires a high-resolution bathymetry and a well-defined geometry of the port

While previous numerical simulations such as those of Wang and Liu (2005), Alasset et al. (2006), and Sahal et al. (2009) have brought considerable insight on this tsunami, all of them have failed in reproducing the exact amplitude of the oscillations and the subsequent resonance phenomena. Such a failure has been attributed to the lack of high-resolution local bathymetry and harbour geometries.

In this work, we investigate for Palma bay and harbour if the above-mentioned failure results from numerical or physical reasons taking advantage of the now available high-resolution bathymetries. To better understand the response of the harbour and its interaction with the larger bay, we have carried out some tests using the known Boumerdès-Zemmouri seismic source, also trying different parameterizations. The comparison of simulations and observations has been eased by the availability of Palma de Majorca tide gauge records. Overall, the Boumerdès-Zemmouri earthquake and associated Western Mediterranean tsunami, and its impact on the Palma bay and harbour, constitute an interesting case for modeling experiments.

The work is mainly focused on the study of the frequency response of Palma harbour to seismic, with a special focus on the 2003 Western Mediterranean tsunami. One of the main objectives is to 
verify a resonance phenomenon by analyzing the transfer of energy of the tsunami from the generation area to the bay and harbour, compared with the natural oscillation modes of both water bodies.

\section{METHODOLOGY}

The computation of the natural modes of resonance (eigenperiods) has been performed at different locations of the harbour and bay by applying the IH-MSP model (Berkhoff, 1972). The numerical simulation of the 2003 Western Mediterranean tsunami has been carried out with the COMCOT (Cornell Multi-grid Coupled Tsunami Model) model using Meghraoui et al. (2004) source, from where energy spectra were obtained for similar locations. The energy distribution by frequencies has been analyzed after comparing natural modes of oscillation and the oscillations generated by the 2003 tsunami. The sensibility analysis of the bathymetry resolution has been conducted on four different sets of grid sizes, with high-resolution bathymetry of Palma bay and harbour compiled within the EU TRANSFER project. The water height and spectra at the tidal gauge in Palma have been compared to the numerical simulations from COMCOT applying Meghraoui's et al. (2004) source model.

The MSP model is based on the Mild Slope Equation of Berkhoff (1972) first developed by Berkhoff (1982) and Behrendt (1984), for studying wave propagation over bathymetries experiencing smooth variations. The version of the MSP model that we have used is the one further developed by IH Cantabria from the University of Cantabria, Spain, hence the acronym IH-MSP. The new model version solves the elliptic form of the equation for linear waves and allows including reflective, absorbing and partly absorbing boundary conditions to define structures and breakwaters inside a harbour. The equation can be expressed as:

$$
\nabla\left(\Gamma C C_{g} \nabla \Phi\right)+\frac{\omega^{2} C_{g}}{C} \Phi=0
$$

where $\nabla=$ gradient operator $[\nabla=(\mathrm{dx}, \mathrm{dy})], \mathrm{G}=$ bottom friction coefficient, $C=$ local phase velocity $(C=w / k), C g=$ group velocity $(C g=d w / d k), \mathrm{w}=$ wave angular frequency $(\mathrm{w}=2 \mathrm{p} / \mathrm{T}), \mathrm{T}=$ wave period, $\mathrm{F}=$ velocity potential, $k=$ local wave number $\left(\mathrm{w}^{2}=\operatorname{gktanh}(k h)\right), g=$ gravitational acceleration, $h(x, y)=$ variable water depth, $a=$ wave amplitude, $\mathrm{x}, \mathrm{y}=$ coordinates axis.

Solving equation (1) requires defining the boundary conditions along the integration domain. The numerical solution of the elliptic equation applies a finite element scheme following Behrendt (1984) for a variable bottom.

The COMCOT model, developed by the School of Civil and Environmental Engineering, Cornell University, is a reference model for tsunami propagation. It has been widely used to investigate the propagation of historical tsunamis such as the 1960 Chilean tsunami (Liu et al., 1994), the 1992 Flores Islands tsunami (Liu et al., 1995), the 2003 Western Mediterranean tsunami (Wang and Liu, 2005; Álvarez-Gómez et al., 2009) and the 2004 Indian Ocean tsunami (Wang and Liu, 2006).

COMCOT solves both non-linear and linear shallow water equations, adopting a modified leapfrog scheme. Its nesting capabilities make it possible to simulate tsunami generation and propagation from the source zone to a given coastal area, considering the inundation of coastal zones. A two-way nesting method is applied for the nested grid system. The finer inner grids adopt smaller grid sizes and time steps compared to their adjacent outer (larger) grids. In the outer grids, at the beginning of each time step, the volume flux is interpolated into their inner (finer) grids. At the end of each time step, the calculated water surface elevations at the inner finer grids are averaged to update the free surface elevations of the larger grids, which are used to compute the volume fluxes at the next time step in the coarser grids. This allows the model to capture near shore features of tsunami propagation with higher grid and time resolution while maintaining computational efficiency (Wang and Liu, 2005).

In the Western Mediterranean region, earthquake generated tsunamis are expected to present wave lengths between $225 \mathrm{~km}$ and $15 \mathrm{~km}$ for water depths between $3000 \mathrm{~m}$ and $10 \mathrm{~m}$, respectively. In these circumstances, wave dynamics can be considered mainly horizontal, being vertical accelerations negligible and, thus, the pressure field can be assumed to be hydrostatic (Wang and Liu, 2005). Propagation of this kind of waves can be correctly simulated using the shallow water wave equations 


\section{Sea level oscillations in Palma bay and harbour}

The Palma float tide gauge recorded sea level oscillations caused by the 2003 Western Mediterranean tsunami at 1' intervals (Fig. 2). The gauge is located at the end of the West Quay in the Palma harbour, at a depth of about $20 \mathrm{~m}$ (Fig. 1).

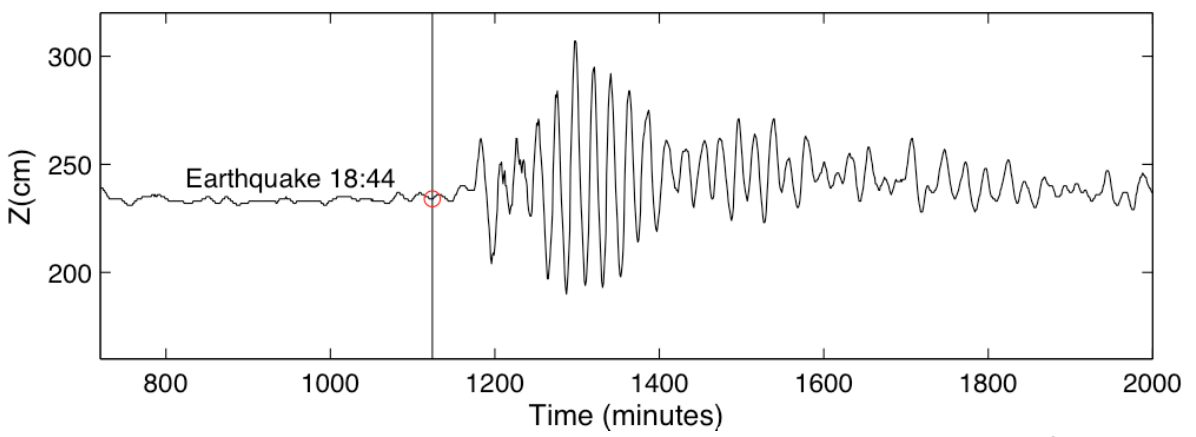

Fig 2. Sea level oscillations during May 2003 tsunami at Palma tide gauge. Time in minutes from 24:00 of 21th of May. Data sampling: $1 \mathrm{~min}$

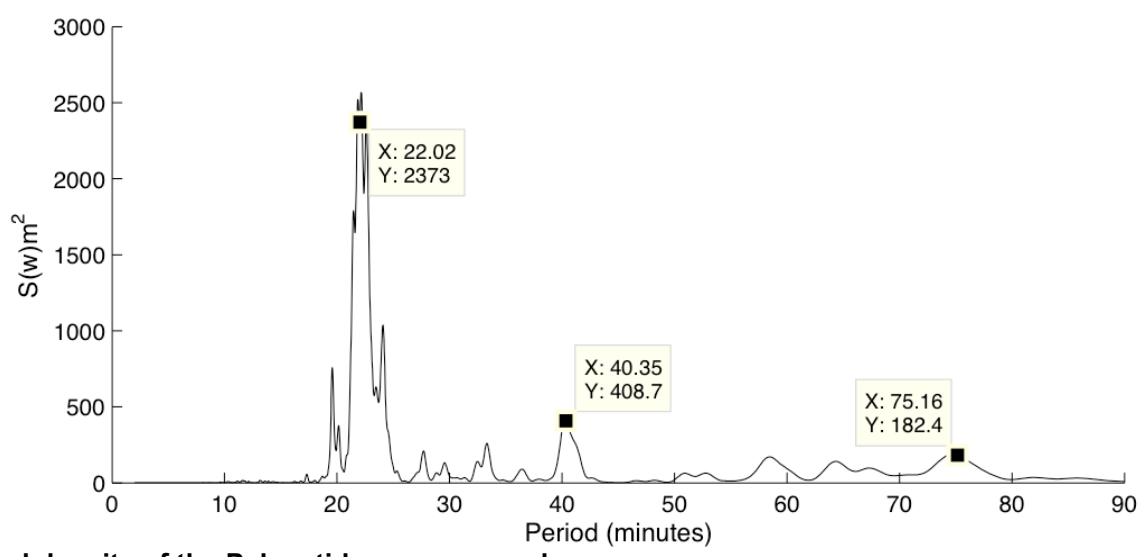

Fig 3. Spectral density of the Palma tide gauge record.

We presume that the maximum total amplitude of $\sim 1.1 \mathrm{~m}$ recorded by the Palma gauge was less than the maximum amplitude achieved in the most damaged areas of the harbour. The spectral analysis of the data shows the main peak of energy at 22' period with other noticeable peaks at $19.55^{\prime}, 40.35^{\prime}$ and 74.81' (Fig. 3). The maximum wave amplitude was reached 110' after the arrival of the tsunami, which showed initial amplitude of only $20 \mathrm{~cm}$ at the Palma harbour tide gauge. This delay points to the occurrence of local resonance, with the larger amplitudes reached inside the harbour caused by local amplification of the tsunami wave.

Such a hypothesis could be checked by performing a study of the natural resonance frequencies of the bay and harbour of Palma by means of numerical simulations, as presented in the next section.

\section{Natural resonance frequencies}

Numerical simulations have been performed with the overall aim of determining the natural modes of oscillation and the main frequencies of response to sea level oscillations in Palma bay and harbour by considering their particular geometry and bathymetry. The final step is identifying the origin of the frequencies present in the tide gauge record and determining if they are a response attributable to the configuration of the bay, the harbour or both. For this we have generated a finite element grid with an average cell size grid of $40 \mathrm{~m}$ in the bay and $10 \mathrm{~m}$ in the harbour and along the coastline (Fig. 4) 


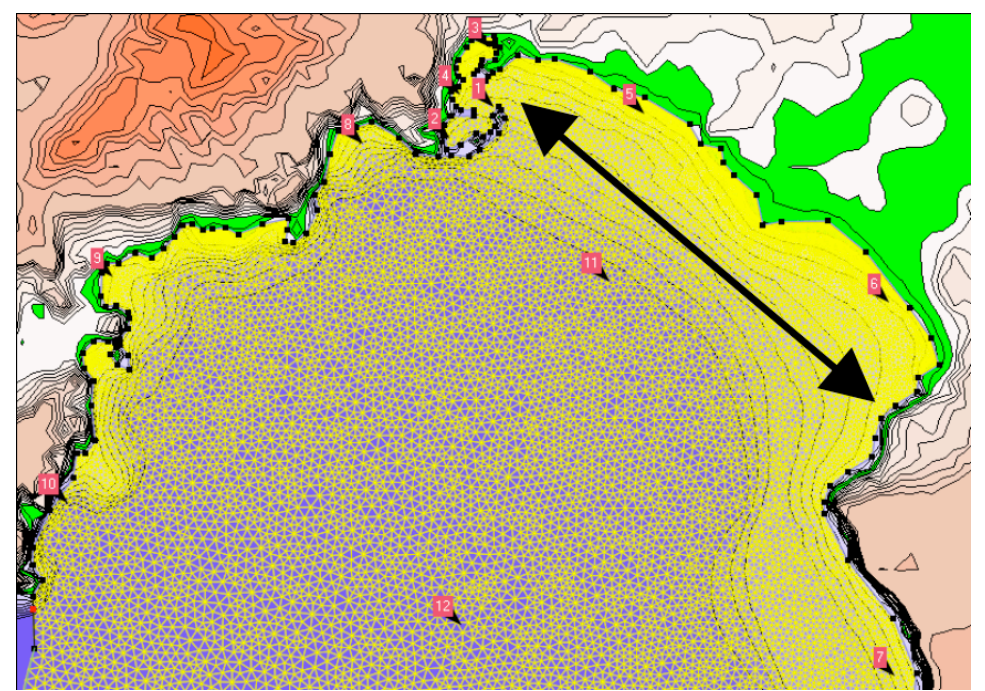

Fig 4. Domain used for IH-MSP simulations for the bay of Palma, with location of the selected synthetic points. Transverse local edge waves shown for the arrow

The IH-MSP model has been forced with a frequency swept ranging from $0.5^{\prime}$ to $120^{\prime}$ periods, with 0.5 ' increments, in order to identify the resonance frequencies in the grid domain. Total reflection has been imposed over the coastal boundaries as we are studying long waves. The elevation time series for some of the synthetic points that have been selected in the grid domain outside the harbour (Fig. 4) are displayed in Figure 5. The plot shows that the main peaks correspond to 6.5', 13', 17', 22' and 41'. For some of the synthetic points there is also one peak at 9.5'. The 22' mode of oscillation coincides exactly with the most energetic one recorded by the tide gauge. It should be noted that some energy peaks appear for $\mathrm{T}^{<} 6^{\prime}$ in points located nearby beach areas (e.g. points $\mathrm{Pb} 5$ and $\mathrm{Pb}$ ) (Figs. 4 and 5).

The main peaks inside the harbour, also considered as part of the bay grid domain in this simulation, correspond to $9.5^{\prime}, 17^{\prime}$ and $22^{\prime}$, the two latter coinciding with synchronous peaks off harbour (Fig. 6). No significant energy amplifications are obtained for T>30'.

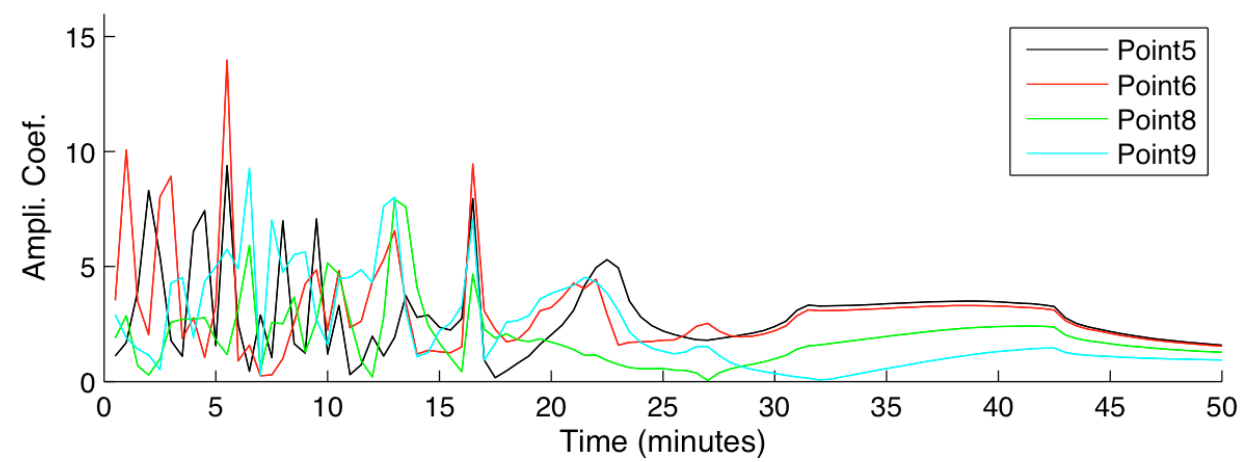

Fig 5. Output of the frequency-amplitude swept simulations, at the selected synthetic points, for the bay of Palma. Several points outside the harbour.

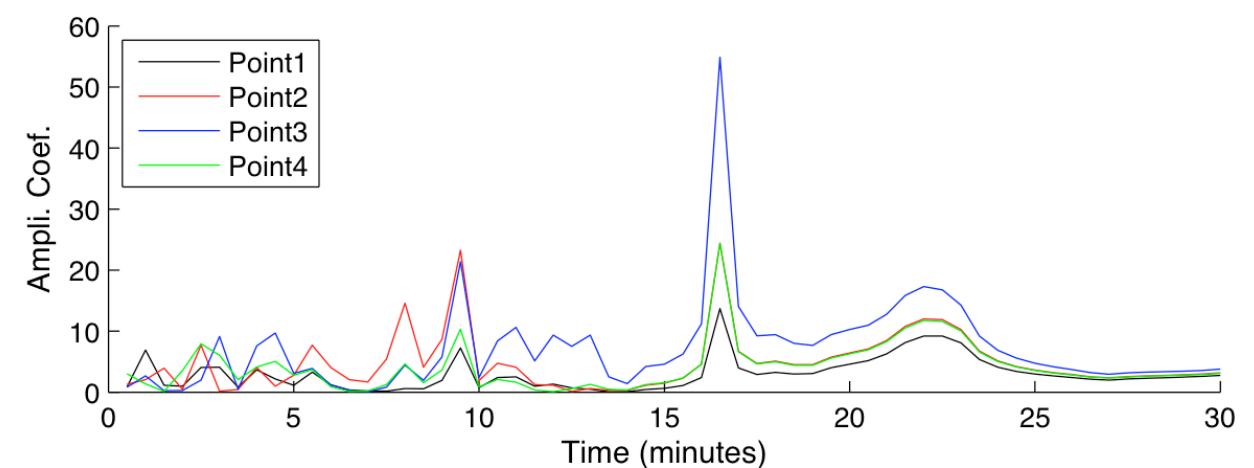

Fig 6. Output of the frequency-amplitude swept simulations, at the selected synthetic points, for the bay of Palma. Several points inside the harbour. 
The spatial distribution of free surface oscillations (i.e. nodes and antinodes) for the main modes of oscillation within the bay and harbour is shown in Figure 7. The 9.5' period results in N-S and NW-SE oscillation waves, the latter between the harbour and the opposite coastline to the SE thus paralleling the sandy beaches closing the bay to the NE. One of the most resonant periods in the bay system (including the harbour) is the $17^{\prime}$ one, with energy amplification being larger outside the harbour, which involves an antinode immediately south of it. Finally, the 22' period results in a NE-SW oriented wave oscillation.
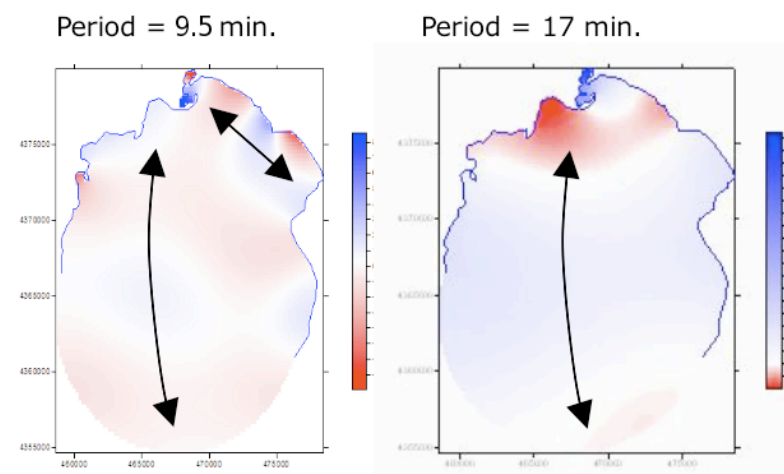

Period $=22 \mathrm{~min}$.

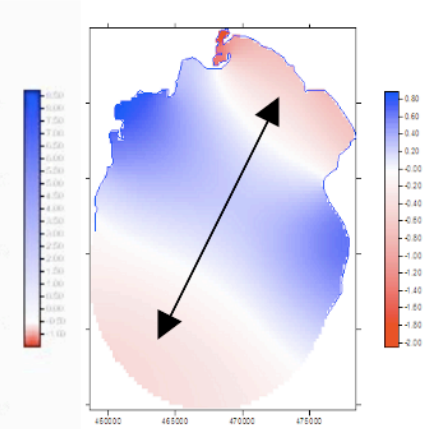

Fig 7. Spatial distribution of nodes and antinodes for the main modes of oscillation identified for the bay of Palma. The arrows indicate the principal direction of the oscillation.

We hypothesize that the energy peaks for $\mathrm{T}<6$ ' obtained for synthetic points in the north-eastern beaches (Fig. 4) and the NW-SE oscillation wave of the 9.5' period (Fig. 7) are caused by the interaction of the harbour, the beaches themselves and the local geometry leading to the generation of transverse or edge waves.

As it could be observed, the location of the Palma tide gauge does not correspond to the highest energy response to any of the frequencies in Figure 7 compared to the northern basin of the harbour. This is an observation to be taken into account when interpreting the results of COMCOT simulations.

The same procedure described above has been followed to analyze the natural oscillations induced within the harbour domain with total reflection in breakwaters and boundaries (Fig. 8). Figure 9 shows the response at some of the synthetic points leading to the identification of main peaks of energy within the harbour at 2', 3.5', 5.5', 6.5' and 12'. Frequencies are higher than in the bay, as it should be expected considering the smaller size of the harbour domain. Free surface oscillations are illustrated in Figure 10 for 2', 6.5' and 12' periods when the maximal oscillations occur at the northern basin where synthetic points $\mathrm{Ph} 9$ to $\mathrm{Ph} 12$ are located. Point $\mathrm{Ph} 10$ corresponds to the Sant Magí dock where serious damages where reported as a result of the 2003 Western Mediterranean tsunami (Figs. 1, 8 and 9). 


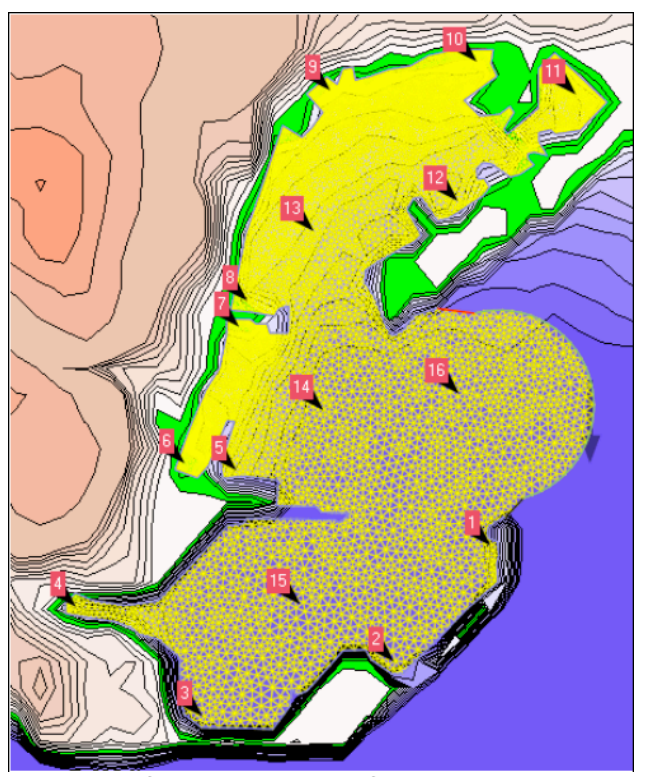

Fig 8. Domain used for IH-MSP simulations for the harbour of Palma, with position of the selected synthetic points.

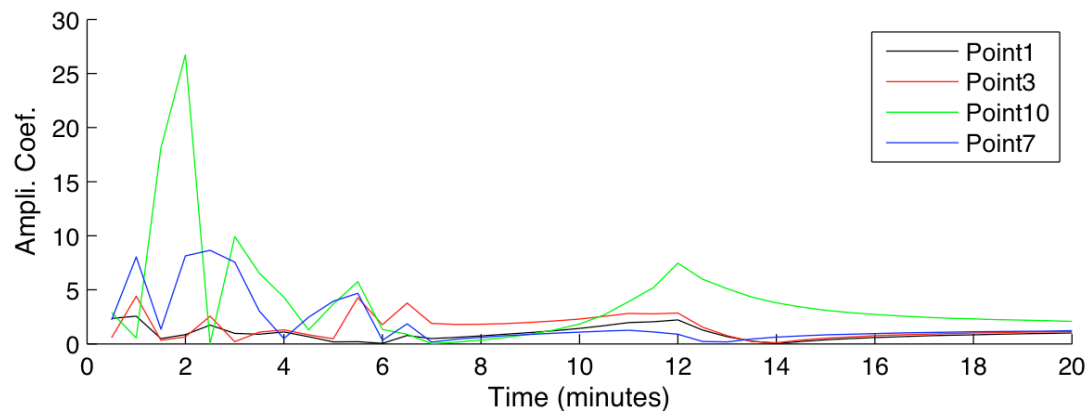

Fig 9. Output of the frequency swept simulations, at some selected synthetic points, for the harbour of Palma.

Energy peaks for periods over 12' have not been found within the harbour domain. However, simulations at the bay scale show that points located within the harbour domain (i.e. points $\mathrm{Pb} 1, \mathrm{~Pb}$, $\mathrm{Pb} 3$ and $\mathrm{Pb} 4$; see Figure 5) present energy at 17' and 22', which likely result from coupling between bay and harbour. In other words, the $17^{\prime}$ and $22^{\prime}$ resonant oscillations are induced by the geometry of the bay in the harbour domain.

The study of the natural resonance frequencies in the Palma bay and harbour shows that the most energetic oscillation periods recorded by the tide gauge (Fig. 3) after the 2003 Western Mediterranean tsunami, and specially the one at 22', are consistent with the natural modes of oscillations within the bay (Fig. 5), and that no apparent resonance is associated to the harbour itself with resonant periods smaller than 12' (Fig. 9). This implies that the wave amplification observed inside the harbour, principally in the most damaged northern basin (Figs. 7 and 10), was generated by a resonance effect induced by the Palma bay. 

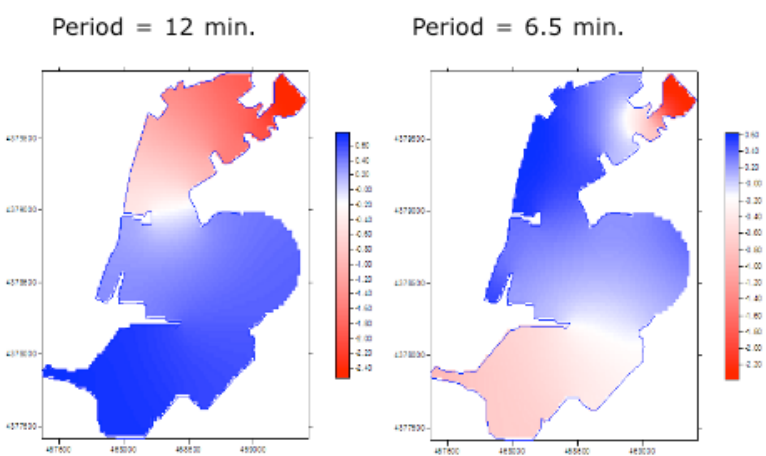

Period $=2 \mathrm{~min}$.

Fig 10. Spatial distribution of nodes and antinodes for the main modes of oscillation identified for the Palma Harbour.

Our results confirm the idea that the Palma tide gauge measurements did not reflect the actual magnitude and impact of the 2003 Western Mediterranean tsunami in the theoretically "more protected" northern basin of the harbour. This is because the 1' recording interval of the tide gauge poorly recorded the 2' frequency of the most energetic peak in the harbour domain (Fig. 9), and the maximum oscillation occurring in the Sant Magí dock of the harbour's northern basin (Fig. 1) was less significant at the tide gauge position.

Finally, the 12 ' period detected over the shelf is associated to edge waves travelling along the island shelf (Fig. 17) whose influence likely is larger on beaches and small embayments along the shoreline than at Palma bay and harbour where the energy amplification is small despite having a natural oscillation mode close to this frequency.

\section{NUMERICAL SIMULATIONS}

The numerical simulation of the 2003 Western Mediterranean tsunami has been carried out with the COMCOT (Cornell Multi-grid Coupled Tsunami Model) model using Meghraoui et al. (2004) source. The tsunami generation mechanism adopts the model of Mansinha and Smyle (1971), assuming that the instantaneous sea surface deformation is equal to sea bottom deformation.

Table 1 and Figure 12 show the four different nested bathymetric grids used for the simulation, ranging in resolution from $720 \mathrm{~m}$ (grid 01 in Fig. 11) to $20 \mathrm{~m}$ inside the harbour (grid 41 in Fig. 11). The bathymetric grids were produced by University of Barcelona after compiling the best available information from open access databases and bathymetric maps, the Spanish EEZ program, "Cartas batimétricas de las Islas Baleares" of the government of the Balearic Islands, proprietary information and "Puertos del Estado". The nonlinear equations were selected for the three inner grids, and the linear approximation for the most external one.

\begin{tabular}{|c|c|c|c|c|c|c|}
\hline Grid & $\mathrm{dx}(\mathrm{m})$ & $\mathrm{dt}(\mathrm{sec})$ & Noc & $5 / y$ & Theroy/Rc & hness \\
\hline 01 & 720 & 0,2 & 1336 & 1336 & Linear & No \\
\hline 21 & 220 & 0,1 & 678 & 504 & NonLinear & 0,001 \\
\hline 31 & 110 & 0,05 & 282 & 232 & NonLinear & 0,001 \\
\hline 41 & 20 & 0,025 & 245 & 232 & NonLinear & 0,001 \\
\hline
\end{tabular}



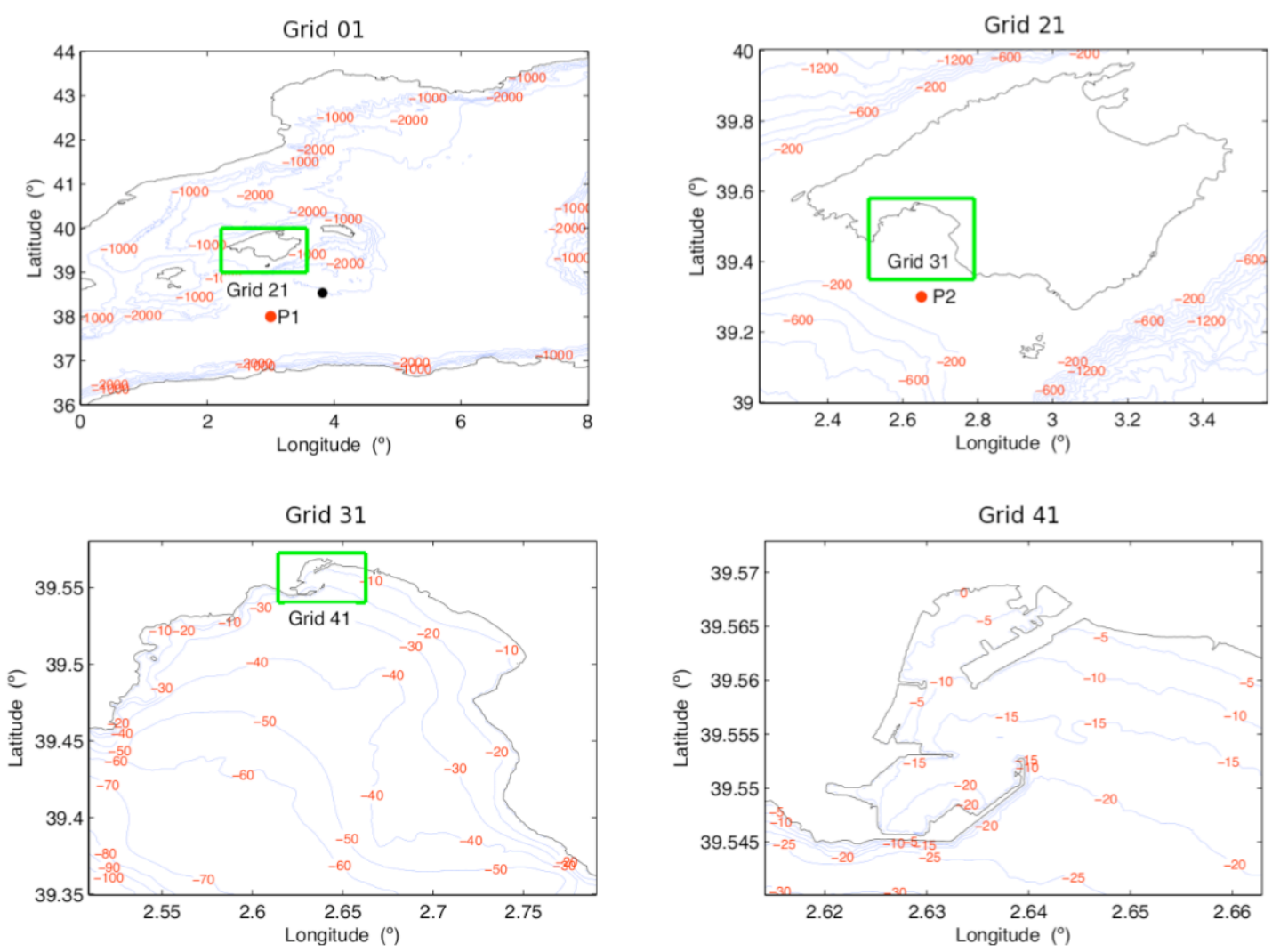

Fig 11. Computational domain. Upper left, Balearic Islands, Grid01. Upper right, Palma de Mallorca Island, Grid21. Bottom left, Palma de Mallorca Bay, Grid31. Bottom right, Palma de Mallorca Harbour, Grid41. Grid01 and Grid21 show the points P1 and P2 located at $2600 \mathrm{~m}$ and $120 \mathrm{~m}$ depth.

Noticeable oscillations remain even three hours after the leading tsunami wave reaches the harbour (minutes 220, 240 of the simulation), which is consistent with observations. This effect is attributed to a resonance phenomenon with an approximated period of 22' (Fig. 13) that appears in both the simulations and the observations and coincides with the second natural oscillation mode of Palma bay, as explained before. None of the simulations show the smaller peaks around $40.45^{\prime}$ and $74.47^{\prime}$ found in the tide gauge data (Fig. 13), which likely result from interactions between the islands' shores and the continental shelf. Longer simulation times would be required to obtain such long periods.

The 12' period peak could be associated to edge waves generated along the island's shelf, which have been identified in the simulations, as shown in Figure 14. The estimated wavelength of these edge waves along the northern Tramontana coast of Majorca is around 20-30 km. It should be noted that this period, which appears in the simulations, does not seem to be of significance in the Palma bay and harbour as inferred from the tide gauge spectra, but it could be of relevance for beaches and small embayments along the island's coast.

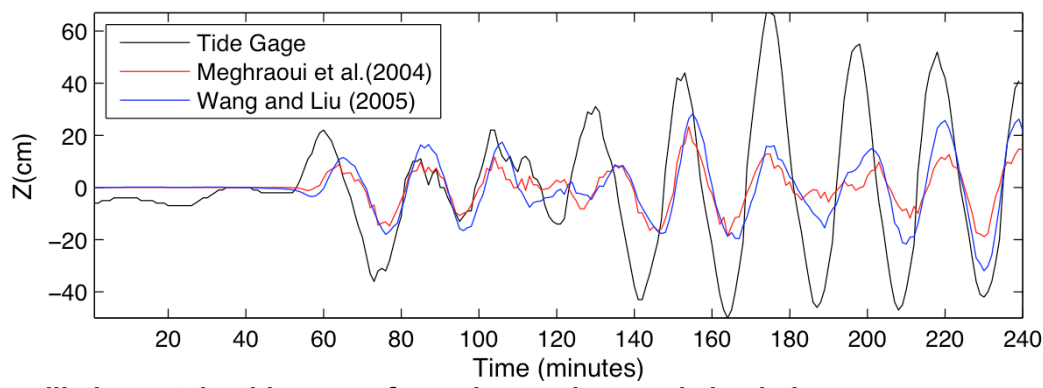

Fig 12. Sea level oscillations at the tide gauge from observations and simulations. 


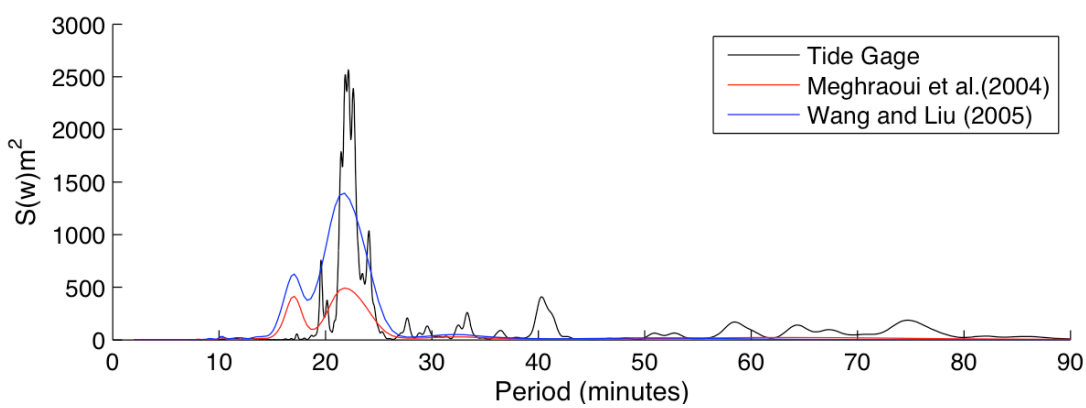

Fig 13. Distribution of spectral energy for sea level oscillations at the tide gauge from observations and simulations.

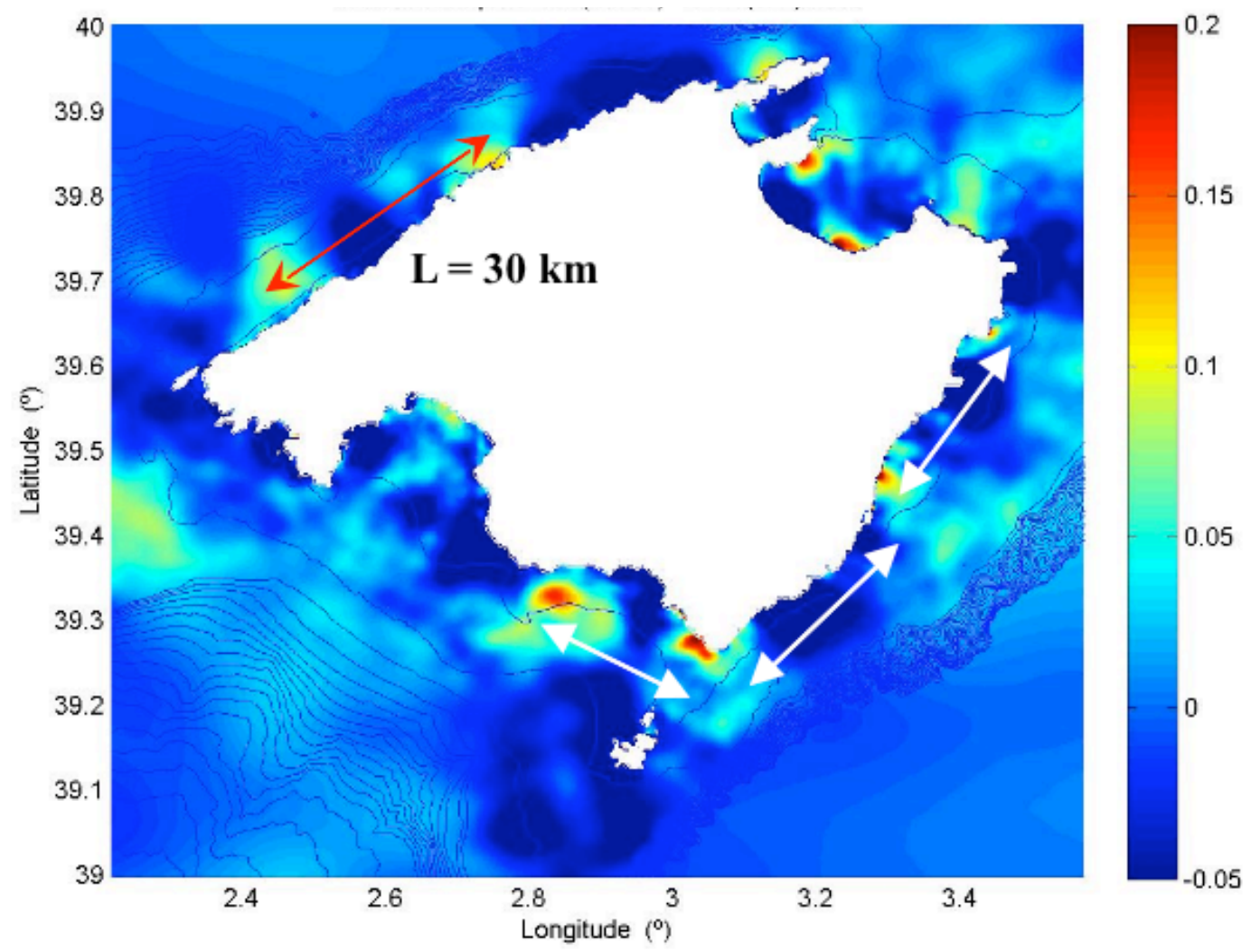

Fig 14. Example of the output of one of the simulations at time $128 \mathrm{~min}$, showing the presence of edge waves propagating around the island, with an approximate period of 12-14 minutes and $30 \mathrm{~km}$ of wavelength in the Tramontana coast. 


\section{CONCLUSIONS}

Energy from the 2003 Western Mediterranean tsunami, as measured by the tidal gauge of Palma harbour, concentrated mainly in 19' and 22' periods (Fig. 3). These periods are close to the natural modes of oscillations of the bay (Fig. 5). No resonance appears to be associated to the harbour itself, with resonance periods less than 12' (Fig. 9). Therefore, we conclude that the observed wave amplification inside the harbour, principally in the northern basin (Figs. 7 and 10), was generated by a resonance effect induced by the Palma bay configuration. The harbour's northern basin corresponds to most seriously damaged area according to the Harbour Authority accounts.

The most energetic peak in the harbour occurs at 2', or even less (Fig. 9), which would be poorly recorded by a 1' sampling interval by the tide gauge. In addition, the maximum oscillation in the northern basin is lessened at the location of the tide gauge, as illustrated by both the bay and harbour domain experiments. It could be then concluded that, even if remarkable, the Palma tide gauge record does not show in full the actual magnitude of the 2003 tsunami at the harbour's dead end. Furthermore, the low period energy peaks within the bay ( $\left(<6^{\prime}\right)$ are associated to a coupling between the harbour and the local geometry in the bay's beach area.

Additionally, edge waves are recorded $\left(12^{\prime}\right)$ generated by waves travelling along the platform around the island (Figure 14).

\section{ACKNOWLEDGMENTS}

This work is a contribution from the EU funded research project TRANSFER (Tsunami Risk And Strategies for the European Region, ref. 037058). MC and JLC acknowledge Generalitat de Catalunya support to CRG Marine Geosciences as an excellence research group (ref. 2009SG R1305). Sea level data from Palma tide gauge have been kindly provided by the Instituto Español de Oceanografía.

\section{REFERENCES}

Alasset, P.-J., Hebert, H., Maouche, S., Calbini, V. and Meghraoui, M. (2006). The tsunami induced by the 2003 Zemmouri earth quake ( $\mathrm{Mw}=6.9$, Algeria): modelling and results. Geophysical Journal International, 166: 213-226.

Álvarez-Gómez, J. A., Olabarrieta, M., González, M., Otero, L., Carreño, E. and Martínez-Solares, J. M. (2009). The Impact of tsunamis on the Island of Majorca Induced by North Argelian Seismic Sources. The Turkish Journal of Earth Sciences (in press).

Dan, G. (2007). Processus gravitaires et évaluation de la stabilité des pentes: approche géologique et géotechnique. Application à la marge algérienne et à l'effondrement de l'aéroport de Nice en 1979. PhD Thesis, UBO, $365 \mathrm{p}$.

Delouis, B., Vallee, M., Meghraoui, M., Calais, E., Maouche, S., Lammali, K., Mahsas, A., Briole, P., Benhamouda, F. and Yelles, K. (2004). Slip distribution of the 2003 Boumerdes- Zemmouri earthquake, Algeria, from teleseismic, GPS, and coastal uplift data. Geophysical Research Letters, 31, L18607, doi:10.1029/2004GL020687.

Jansa, A., Monserrat, S. and Gomis, D. (2007). The rissaga of 15 June 2006 in Ciutadella (Menora), a meteorological tsunami. Advanced Geosciences, 12: 1-4.

Liu, P. L.-F., Cho, Y.-S., Yoon, S.-B. and Seo, S.-N. (1994). Numerical simulations of the 1960 Chilean tsunami propagation and inundation at Hilo, Hawaii. In Recent Development in Tsunami Research, edited by M. I. El-Sabh; Kluwer Academic Publishers, p. 99-115.

Liu, P. L.-F., Cho, Y.-S., Briggs, M.J., Synolakis, C.E. and Kanoglu, U. (1995). Run-up of Solitary Waves on a Circular Island, J. Fluid Mechanics, vol. 302, pp. 259-285.

Losada, M., Vidal, C. and Medina, R. (1989). Experimental study of the evolution of a solitary wave at an abrupt junction. Journal of Geophysical Research, 94 (10): 14,557-14,566.

Meghraoui, M., Maouche, S., Chemaa, B., Cakir, Z., Aoudia, A., Harbi, A., Alasset, J.-P., Ayadi, A., Bouhadad, Y. and Benhamoud, F. (2004). Coastal uplift and thrust faulting associated with the $\mathrm{Mw}$ $=6.8$ Zemmouri (Algeria) earthquake of 21 May. Geophysical Research Letters, 31, L19605, doi:10.1029/2004GL020466.

Monserrat, S., Vilibic,I. and Rabinovich, A.B. (2006). Meteotsunamis: atmospherically induced destructive ocean waves in the tsunami frequency band. Natural Hazards and Earth System Science, 6: 1035-1051

Sahal, A., Roger, J., Allgeyer, S. et al. (2009) The tsunami triggered by the 21 May 2003 BoumerdèsZemmouri (Algeria) earthquake: field investigations on the French Mediterranean coast and tsunami modelling, 1823-1834. Natural Hazards and Earth System Science 
Wang, X. and Liu, P.L.-F. (2005). A Numerical Investigation of Boumerdes-Zemmouri (Algeria) Earthquake and Tsunami. Computer Modeling in Engineering \& Sciences, 10 (2): 171-183.

Wang, X. and Liu, P.L.-F. (2006) An analysis of 2004 Sumatra earthquake fault plane mechanisms and Indian Ocean tsunami. Journal of Hydraulic Research, 44(2): 147-154.

Yagi, Y. (2003). Source process of large and significant earthquakes in 2003. Bulletin of the International Institute of Seismology and Earthquake Engineering, XX: 145-153. 